\title{
O museu de museus de Mabe Bethônico
}

\section{Vivian Horta ${ }^{1}$}

Resumo: Investigação da relação entre museumuseu, projeto artístico de Mabe Bethônico, e o conceito de arquivo na arte contemporânea brasileira, sob a luz do "mal de arquivo", de Jacques Derrida. Discutindo o papel de museus e arquivos como instituições legitimadoras de discursos, a obra da artista propõe a possível construção de ficções através de documentos concretos.

Palavras-chave: Mabe Bethônico, museumuseu, museu, arquivo público

\section{Mabe Bethônico and a museum's museum}

Abstract: Investigation about the relationship between museumuseu, Mabe Bethônico's artistic project, and the concept of archive in contemporary Brazilian art, in the light of the "archive fever", by Jacques Derrida. Discussing the role of museums and archives as institutions that legitimize narratives, the artist's work proposes the possible construction of fictions using concrete documents as means.

Keywords: Mabe Bethônico, museumuseu, museum, public archive

1 Doutoranda em Artes Visuais pelo PPGAV/EBA/UFRJ, onde pesquisa a musealização de performances sob orientação do prof. Dr. Ivair Júnior Reinaldim. Mestre pelo mesmo programa, onde desenvolveu pesquisa, sob orientação de Maria Luisa Luz Távora, que resultou na exposição «Coleção Castro Maya: a Sociedade dos Cem Bibliófilos do Brasil em Destaque». Museóloga Chefe da Divisão de Processos Museológicos dos Museus Castro Maya-IBRAM, desde 2013. Museus Castro Maya - IBRAM. E-mail: vivianhorta@gmail.com. ORCID: https://orcid. org/0000-0001-9334-5523. Lattes iD: http://lattes.cnpq.br/7786772531167942. Rio de Janeiro, Brasil. 


\section{museumuseu - o jornal}

Iniciado por Mabe Bethônico no ano de 2000, museumuseu caracteriza-se como uma estrutura que articula coleções, atividades, textos e imagens, organizados em quatro núcleos. Constitui-se pela prática contínua de pesquisa, acúmulo, coleção, classificação e criação de novos sistemas a partir de objetos e documentos deslocados de seu contexto original. O projeto lida com limites entre ficção e realidade, documentação e construção, questionando a transformação de informações concretas em narrativas selecionadas. Em 2006, o projeto foi exibido na $27^{a}$ Bienal de São Paulo, deslocando assim seus arquivos para uma apresentação acessível ao público fisicamente.

As migrações no espaço e no tempo identificadas neste estudo de caso apresentam-se como instrumentos à reflexão acerca da transformação de

\section{nuseumused}

Figura 1

Mabe Bethônico - museumuseu (jornal impresso),

2016

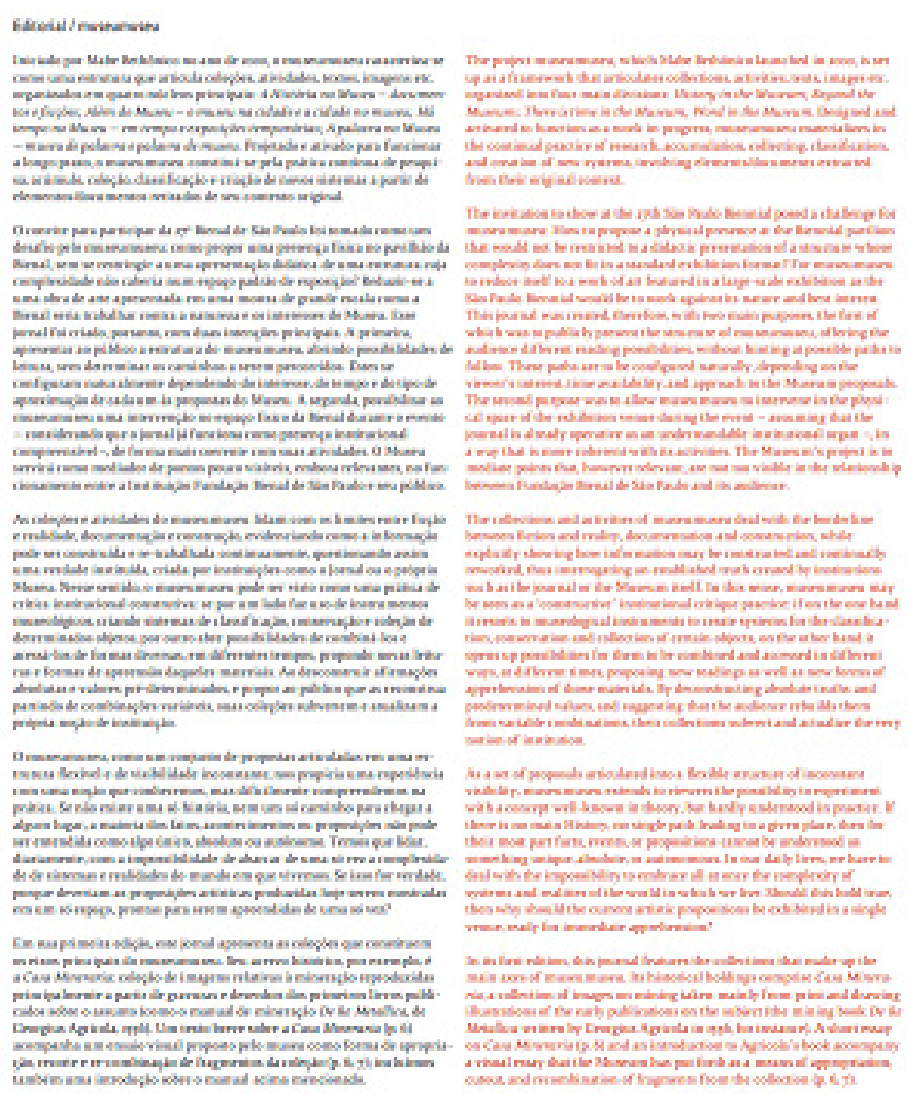


ideias, objetos e imagens ocorrida durante a lacuna exposta pelo trânsito destas obras, desde sua criação até sua exibição ao público.

Para compreender o projeto museumuseu em sua totalidade, é necessário abordar três camadas de sentido, cada uma com sua curadoria particular. Através destas camadas, Bethônico reflete acerca do conceito de arquivo, do arquivo no Brasil e, sobretudo, utiliza-se da construção de narrativas ficcionais para fazer uma arte que critica e questiona, de maneira irreverente, porém objetiva, as negociações envolvidas no processo de construção, consulta e utilização dos arquivos públicos brasileiros.

O primeiro número do jornal museumuseu, publicado por ocasião do convite para participação da artista na $27^{a}$ Bienal de São Paulo, é composto de textos, fotografias e tabelas que ilustram o que é chamado por Ana Paula Cohen, em seu Editorial , de "eixos principais do museu". Alguns destes eixos são a Casa Mineraria - o acervo histórico do museumuseu - representada, no jornal, por um texto e um breve ensaio visual, proposto como forma de apropriação; O Colecionador, um personagem fictício que recorta imagens de jornal desde 1996 e os divide em quatro grupos - Destruição, Corrosão, Construção e Flores -, que é apresentado no jornal através de um ensaio crítico que propõe uma leitura sobre a coleção; O Módulo Itinerante do Museu do Sabão, onde textos e imagens indicam o "conteúdo museológico" do supracitado museu, que conta com doações dos visitantes para incrementar sua coleção, e até uma coleção formada pelos caracteres utilizados na escrita dos textos do jornal.

Além de toda a sistematização baseada em termos e técnicas utilizados na prática museológica, todos os eixos propostos ainda contam com uma espécie de curadoria de seu conteúdo, expressa objetivamente através do Editorial da publicação.

Quando Bethônico cria museus dentro de um museu - ou coleções dentro de uma coleção, arquivos dentro de um arquivo -, propondo "leituras" e "formas de apropriação", está colocando em jogo as infinitas narrativas cujas construções são possíveis através de um mesmo conjunto de documentos.

Busco formular certas perguntas antes de iniciar as pesquisas e por muito tempo este questionamento se dirigia à própria estrutura do arquivo. Desde a organização, as fissuras, seu uso, e a estrutura em torno, de materiais, mas sobretudo de indivíduos em suas diversas funções, mantenedoras e editoras dos materiais. Aos poucos o trabalho expandiu para uma maior "ficcionalização", quando relações se 


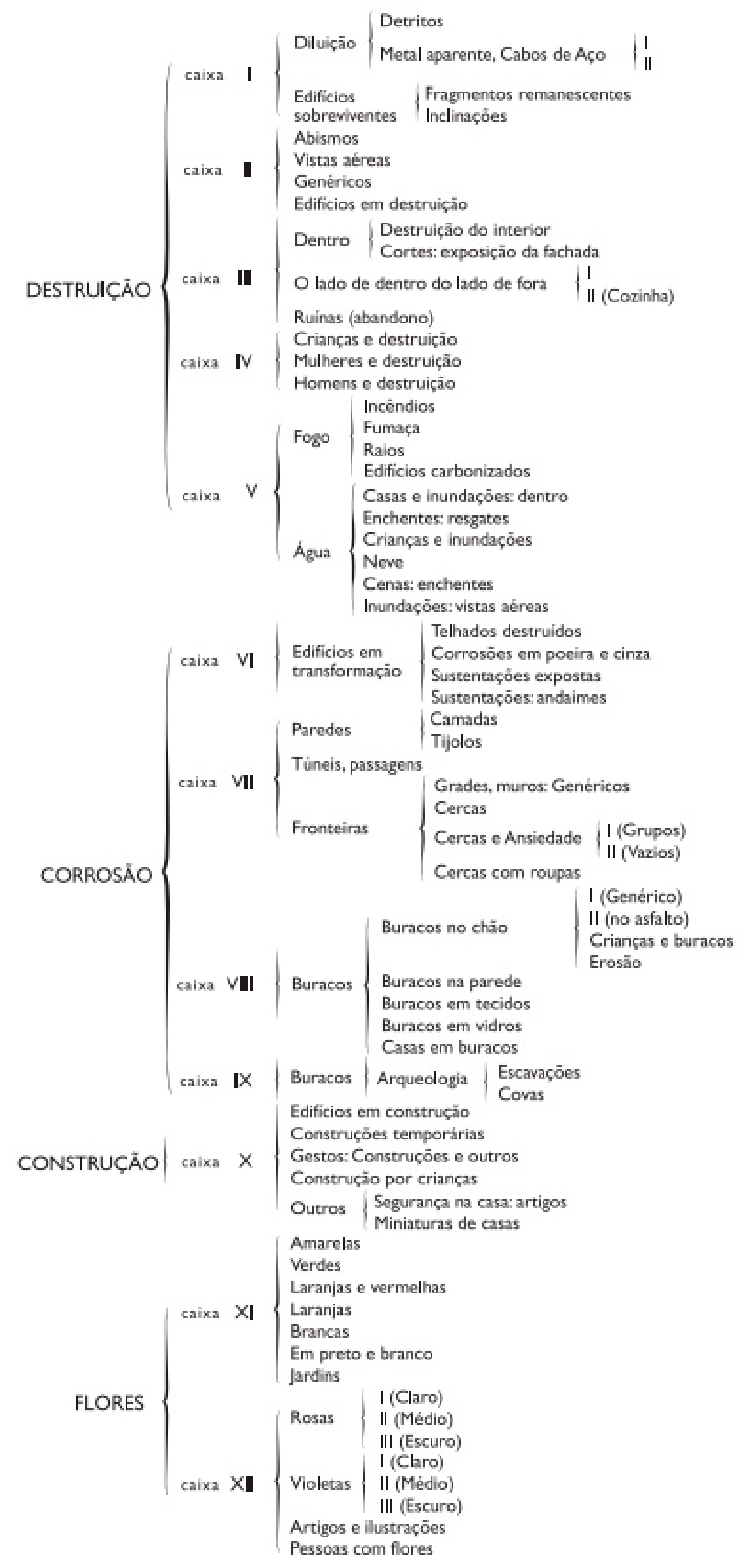


construíram para além do contexto onde estavam os documentos, seja a instituição de guarda do material, ou os sistemas em torno dos documentos. De modo a possibilitar apropriações dos documentos, para usos distantes de suas fontes de origem, numa discursividade deslocada e descomprometida com sua origem.

Desta forma, o museumuseu de Mabe Bethônico utiliza o arquivo em sua obra, ao mesmo tempo em que, apropriando-se dele, o questiona, e acaba por construir novos arquivos, novas histórias. $O$ jornal propõe indiretamente uma discussão a respeito da questão dos arquivos no Brasil, um país marcado por um longo período de repressão militar. Naquele momento, a relação de pesquisadores e cidadãos em geral com instituições que concentravam a informação de interesse público foi marcada por limitações, impostas por grupos dominantes que atendiam a interesses específicos e suprimiam documentos e informações destes arquivos, para contar a História à sua própria maneira.

Em Latin American Art History: An Historiographic Turn, Andrea Giunta e George F. Flaherty discorrem a respeito do contexto político nas décadas anteriores à de 1980 na América Latina, e sobre sua relação com o acesso aos arquivos públicos no continente:

In the last twenty years, the history of Latin American art ceased to be a discipline of connoisseurship and reconstituted itself as a social science. The impact of cultural studies, interdisciplinary research, and the expansion of the field in the wake of the reestablishment of democracy in Latin America since the 1980s made this radical paradigm change possible. It is essential to remember the repressive climate of the Latin American dictatorships (and other authoritarian and neocolonial regimes) in order to understand the paralysis produced by those years, in which posing questions or pursuing investigations were dangerous activities in themselves. Both art criticism and archives were under government control or influence. Democratic opening enabled the revision of plans of study and resources for research, as well as the creation of multiple new archives throughout the Americas.

Recent research has treated these archives not only as national or universal patrimony but also as critical repositories for the rethinking of dominant historiographic paradigms.

Como veremos a seguir, as dificuldades e peculiaridades retratadas por Bethônico em sua obra denotam a maneira como estas práticas refletem, ainda nos dias de hoje, a relação entre interesses privados e patrimônio público no Brasil. Em mais um dos atravessamentos entre a História e a obra de Mabe, a própria Bienal de São Paulo sofre, durante as décadas de 1960 e 1970, forte repressão e censura por parte da ditadura militar instaurada no país.

Além da curadoria proposta pelo jornal impresso, que elenca módulos deste fantasioso museu de museus através de textos, temos outras duas camadas 
de sentido, propostas dentro do mesmo emaranhado de narrativas. A segunda é constituída pela organização de cada uma das coleções, que, como exposições com recortes específicos, são propostas por diferentes curadores, através de textos, fotos ou gráficos. Neste sentido, Bethônico utiliza-se com consistência da técnica museológica, seja organizando o Módulo Itinerante do Museu do Sabão em uma espécie de reserva técnica, criando um Tesauro para O Colecionador, ou um Glossário de termos museológicos.

Utilizo ainda uma estrutura museológica para organizar a prática sobre instituições, é um lugar em que os trabalhos se relacionam: registros de intervenções em museus e arquivos existentes e criações de instituições: o museumuseu.

A obra de Mabe Bethônico parece transparecer uma busca por tornar público o conteúdo dos arquivos, por desvelar os mais burocráticos processos técnicos de museus, arquivos e bibliotecas, com o intuito de despi-los da aura de mistério, transformando-os em algo mundano. Esta faceta de seu trabalho é bastante perceptível através da relação que trava com o Arquivo Histórico Wanda Svevo, da Fundação Bienal, por ocasião da $27^{a}$ Bienal de São Paulo.

O Arquivo Wanda Svevo é a instância permanente da Fundação Bienal de São Paulo desde sua instauração; onde está depositada a memória de produção dos eventos: fotografias, comunicações com artistas e curadores, documentos de divulgação e catálogos publicados, além de biblioteca especializada. Apesar de sua importância, o arquivo é utilizado sobretudo internamente e é desconhecido pelo público que frequenta os eventos, apesar de estar localizado no segundo andar do edifício, tendo uma porta que sai ao lado do banheiro feminino do pavilhão. O arquivo até então não havia participado dos eventos e o trabalho foi feito em três eixos: primeiramente registramos como o arquivo é abordado por telefone, colecionamos as perguntas dirigidas por pesquisadores e curiosos, buscando identificar o que é normalmente procurado, as demandas e entendimento geral que se tem a seu respeito. Em segundo lugar, fizemos uma campanha através de série de cartazes anunciando endereço, contato, etc. Finalmente, durante a exposição fizemos visitas guiadas, levando o público a conhecer o arquivo pela porta acessível pelo pavilhão. $O$ trabalho serviu para o reconhecimento da Bienal sobre esse espaço, foi preciso adequá-lo fisicamente para visitação de público e cada instância de negociação para a execução do projeto foi um processo de questionamento.

Dentro do projeto museumuseu, a artista propõe uma intersecção entre Arte e Memória, transformando o acanhado, porém extremamente relevante Arquivo em parte do circuito expositivo da Bienal, através de uma ficção sob sua autoria. A artista extrapola os limites entre o Arquivo e o Pavilhão da Bienal, levando para o espaço expositivo desenhos esquemáticos que exibem toda a organização e localização dos documentos que integram o acervo arquivístico.

Wanda Svevo, então secretária geral da Bienal, foi responsável pela criação 
de um arquivo que tinha como propósito dar suporte a pesquisadores e curadores da Bienal. Uma de suas iniciativas mais marcantes foi a de enviar formulários para artistas de todo mundo, solicitando o preenchimento dos campos e o envio de qualquer material de referência sobre seus trabalhos, como biografias e catálogos. Não havia precedentes, até então, para tal medida em museus ou arquivos de arte da América. A partir da década de 1970, porém, o Arquivo é transferido para uma sala fechada, em situação inadequada, onde permanece fora de acesso por cerca de 20 anos . Desta forma, a iniciativa de Mabe Bethônico, mesmo após a reabertura do Arquivo, de deslocá-lo para dentro da $27^{\mathrm{a}}$ Bienal, através da realização de visitas mediadas por ela, é portadora de um tom de desafio às regras e ao silêncio imposto neste período. Quando perguntada pela pesquisadora Ana Pato sobre este caráter performático de algumas de suas obras, Mabe Bethônico afirma que:

\begin{abstract}
A fala pode ser uma instância de re-inscrição do documento, [...] "encenação" do documento, como um recurso para retirá-lo de um estado de dormência, se podemos dizer assim. O trabalho seria uma invenção sobre o resíduo documental, ou a partir dele, e que exige necessariamente uma contextualização, lembrando que ali está a ser discutido uma parte, de algo que não se pode resgatar por inteiro. É esse território potencial de ficção em torno do documento que dispara a construção dos trabalhos. É ainda o contraponto ao silêncio, ao esquecimento; através desse pretexto para uma discursividade.
\end{abstract}

Assim, a artista discorre sobre o que nos parece ser o ponto de partida de seu trabalho com a questão do arquivo: a intenção de recuperar e trazer à luz o que eles guardam. Para além, quando cita o arquivo como emblema de algo que "não se pode resgatar por inteiro", Bethônico tangencia as teorias de Derrida sobre o "mal de arquivo". Segundo o filósofo, sofrer deste mal

É arder de paixão. É não ter sossego, é incessantemente, interminavelmente procurar
o arquivo onde ele se esconde. [...] É dirigir-se a ele com desejo compulsivo, repetitivo
e nostálgico, um desejo irreprimível de retorno à origem, uma dor da pátria, uma
saudade de casa, uma nostalgia do retorno ao lugar mais arcaico do começo absoluto.

Donald Preziosi refere-se ao caráter de uma obra no museu como simultaneamente "referencial" e "diferencial", no sentido de que sua presença denota em si mesma sua incompletude. Ainda, Seligmann-Silva refere-se à arte contemporânea como momento em que

os artistas vão embaralhar os arquivos, vão pôr em questão as fronteiras, vão tentar abalar poderes, revelar segredos, reverter dicotomias, para as explodir. A palavra de ordem é anarquivar para recolecionar as ruínas dos arquivos e reconstruí-las de forma crítica" 
Quanto mais se conta detalhes, mais se evidencia aqueles que não são contados. Mabe Bethônico afirma sua visão do arquivo como suporte para narrativas ficcionais e, por vezes, enviesadas, quando discorre a respeito da decisão de não-utilização de determinados itens de propriedade do Arquivo Wanda Svevo em seu trabalho para a $27^{\text {a }}$ Bienal de São Paulo.

\begin{abstract}
Algumas pessoas da instituição tinham conhecimento dos documentos e histórias que eu escolhi para trabalhar num primeiro momento, mas era difícil lidar com materiais que talvez não deveriam sequer estar ali guardados, ou que foram reunidos de modo polêmico. [...] exibi-los seria afirmá-los publicamente e a decisão foi que eles deveriam permanecer esquecidos. As discussões geradas eram parte importante do projeto, mas uma vez que todos se posicionavam contrários à ação proposta e à exposição das questões ali presentes, o que se configurou não foi uma negociação propriamente. Ao final não houve maior compreensão sobre o lugar, mas a insistência no esquecimento ou adiamento.
\end{abstract}

Neste sentido, seu trabalho também coloca em destaque o apagamento promovido pela decisão de uma instituição de caráter arcôntico que acaba por decidir qual será a narrativa privilegiada através da construção de um determinado arquivo que opta por contemplar, por exemplo, apenas um ponto de vista de determinado evento.

\begin{abstract}
Aos cidadãos que detinham e assim denotavam o poder político reconhecia-se o direito de fazer ou de representar a lei. Levada em conta sua autoridade publicamente reconhecida, era em seu $\operatorname{lar}[. .$.$] que se depositavam então os documentos oficiais.$ [...] Não eram responsáveis apenas pela segurança física do depósito e do suporte. Cabiam-lhes também o direito e a competência hermenêuticos. Tinham o poder de interpretar os arquivos.
\end{abstract}

Assim, podemos depreender que o museu opera na contemporaneidade como o arconte, a instituição que decide o que deve ser esquecido e o que deve ser lembrado. E de que forma deve ser lembrado. No entanto, o museu, assim como o arconte, não possui o acontecimento arquivável. Porque ninguém pode possuir um acontecimento. Porque o acontecimento é experiência. E a experiência essencial não é passível de repetição. Derrida nos esclarece que o arquivo é, em si, repetição.

Tomemos a afirmação de Barthes a respeito da fotografia como documento, De acordo com o autor, ela

[...] reproduz ao infinito [o que] só ocorreu uma vez: ela repete mecanicamente o que nunca mais poderá repetir-se existencialmente. [...] ela reduz sempre o corpus de que tenho necessidade ao corpo que vejo; ela é o Particular absoluto, a Contingência soberana, fosca e um tanto boba [...]. 
Assim, podemos depreender que a tentativa institucional de arquivar uma obra de arte efêmera, como o projeto museumuseu é, em diversos aspectos, leva apenas ao registro da referida obra vista por um determinado ângulo, ou através do olhar de um indivíduo ou de um grupo de indivíduos. A obra em si mesma, fugaz, repleta de sensações e emoções, jamais poderá ser arquivada, já que lhe falta suporte. Paralelamente ao mostrado pelo projeto de Bethônico, também a institucionalização de uma obra de arte efêmera dá conta apenas de um ângulo daquela obra. No entanto, geralmente não fornece suporte suficiente para que se construam novas narrativas baseadas em diferentes subjetividades.

Desta forma, a compulsão que acomete às instituições contemporâneas, no intuito da manutenção de obras de arte efêmeras a partir de registros documentais, vestígios ou fotografias pode ser compreendida como uma resposta à "pulsão de morte" de Freud, que é também uma "pulsão de destruição", que age destruindo o arquivo mesmo antes que este tenha encontrado o exterior.

Este temor pela perda da memória é, segundo Derrida, causa essencial do "mal de arquivo", ao mesmo tempo em que é o próprio motivo pelo qual este arquivo nunca se completa, tendo em vista que "o arquivo, se esta palavra ou esta figura se estabiliza em alguma significação, não será jamais a memória nem a anamnese em sua experiência espontânea, viva e interior."

Retomemos a questão da institucionalização da arte efêmera. Em suas diversas manifestações no contexto institucional contemporâneo, esta prática torna recorrente a problematização a respeito da forma correta de se registrar ou documentar estas manifestações artísticas. Ao entrar em contato com o pensamento de Derrida acerca do "mal de arquivo", uma outra análise desta relação arte-museu torna-se possível. Para o autor,

[...] a estrutura técnica do arquivo arquivante determina também a estrutura do conteúdo arquivável em seu próprio surgimento e em sua relação com o futuro. $O$ arquivamento tanto produz quanto registra o evento.

Não sendo capaz de capturar toda a essência de um acontecimento, o arquivamento acaba por colocar em uma espécie de redoma vestígios que futuramente serão entendidos como o acontecimento em sua totalidade.

Ao discorrer sobre quatro fotografias tiradas em Auschwitz, em 1944, por um fotógrafo desconhecido, Didi-Huberman reconhece sua "relação fragmentária e lacunar com a verdade de que são testemunho" 
O autor analisa duas tendências em relação a estas imagens. Por um lado, espera-se extrair delas "toda a verdade", esperança que apenas pode gerar decepção, visto que trata-se de "fragmentos arrancados, pedaços peculiares", especialmente diante daquilo que se sabe a respeito do terror dos campos de concentração na Alemanha de Hitler.

Outras vezes pedimos muito pouco às imagens: ao relegarmo-las imediatamente para a esfera do simulacro - o que é algo difícil, verdade seja dita, neste caso,excluímo-las do campo histórico. Ao relegarmo-las imediatamente para a esfera do documento - o que é mais fácil e mais usual -, separamo-las da sua fenomenologia, da sua especificidade, da sua própria substância. Em qualquer dos casos o resultado será idêntico: o historiador fica com o sentimento de que 'o sistema concentracionário não se ilustra', que 'as imagens, qualquer que seja a sua natureza, não podem contar aquilo que se passou'.

O descompromisso declarado de Mabe Bethônico e sua obra museumuseu - ou o complexo de sentidos constituído por módulos expositivos, jornal e exibição do Arquivo Wanda Svevo na $27^{\mathrm{a}}$ Bienal de São Paulo - com a reconstituição ou a ilustração de uma realidade teoricamente representada pelo arquivo, e sua substituição por uma obra ficcional que se apropria de fragmentos para criticar o próprio conceito de arquivo torna sua obra, e especialmente o jornal, um exercício metalinguístico de arte e arquivo, capaz de ilustrar a produção e as discussões da arte contemporânea no Brasil.

\section{Considerações finais}

O exercício de análise da obra museumuseu (2006), de Mabe Bethônico, que envolve um complexo de obras e propostas artísticas sob um mesmo
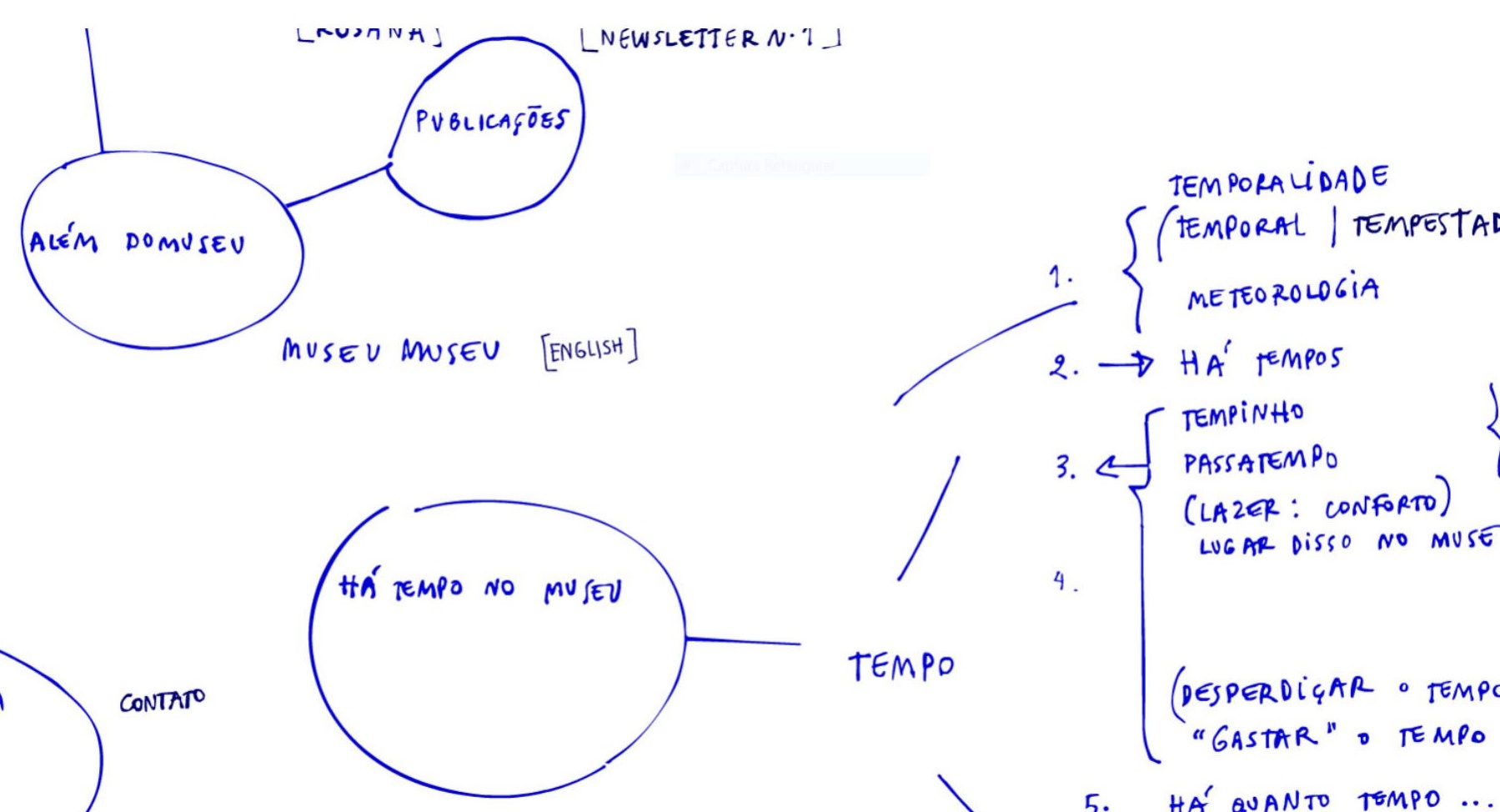

5. HA' QUANTO TEMPO ... 
título, é de razoável complexidade. Os trabalhos da artista ganham enorme força quando conjugado com seus - e de outros - textos, o que chama bastante atenção. Bethônico afirma utilizar a palavra, seja ela em narrativa falada ou em texto escrito, para, por vezes, transformar em ficção ou historicizar negociações envolvidas em seu trabalho, ao mesmo tempo em que o texto - o produto final - acaba por tornar-se um novo trabalho.

\begin{abstract}
A palavra é elemento que perpassa todo meu trabalho. Inicialmente, o que impulsionava a produção eram histórias, mais ou menos evidentes, pouco identificáveis no trabalho final, em que palavras eram indicativas de um todo que era subtraído. Depois, lidava com histórias dos próprios processos de negociação [...], e também ficções. Em palestras e encontros observava que a narração derivada da construção dos trabalhos era parte constitutiva dos trabalhos, e tomava essas instâncias para elaborar conteúdos, e não apenas para descrever processos. [...] Além disso, a credibilidade da palavra do artista - a tradução instaurada no campo da criação é legítima? - Mas existe outro modo de se traduzir que não no território da invenção?1
\end{abstract}

Diante de outros artistas brasileiros que, na contemporaneidade, utilizam-se do conceito de arquivo para desenvolver suas poéticas, como Laura Lima, Paulo Bruscky e Paulo Nazareth, Bethônico demonstra notável irreverência. Sua prática artística envolve os arquivos, porém não é portadora da obsessão pelo autorregistro. Enquanto propõe, por exemplo, leituras para módulos de museumuseu, a artista deixa transparecer a possibilidade de diferentes construções tendo como suporte o mesmo material.

Embora seu trabalho possua caráter efêmero, Mabe não nos parece, em nenhum momento, querer desempenhar ou buscar por algo que desempenhe o papel de arconte de sua obra. Da mesma forma como joga com os fragmentos de outros, deixa fragmentos com os quais outros poderão jogar, encaixando-os da forma que lhes for mais conveniente, dando a eles novas formas e sentidos. O sentido marcadamente político e questionador de sua obra, e sua relação com questões nacionais brasileiras, faz com que sua obra seja portadora e representativa do sentido da arte contemporânea brasileira do seu tempo. 


\section{Referências}

BARTHES, Roland. Capítulo I In: A Câmara Clara: nota sobre a fotografia, Rio de Janeiro, 2015, p. 13-54.

BETHÔNICO, Mabe; COHEN, Ana Paula (Ed.). museumuseu, São Paulo, outubro de 2006. Ano 01, n. 1. Disponível em: https://www.ufmg.br/museumuseu/bienal/jornal/museumuseu.pdf. Acesso em 10 mar. 2020.

BETHÔNICO, Mabe. (entrevista). Museologia \& Interdisciplinaridade - Revista do Programa de Pós-Graduação em Ciências da Informação da Universidade de Brasília, v.l e II, n. 5, maio/junho, 2014. Disponível em: https:// periodicos.unb.br/index.php/museologia/article/view/15484/13782. Acesso em 10 mar. 2020.

BETHÔNICO, Mabe. (entrevista). Perguntas para Mabe Bethônico Respostas para Ana Pato. Anais do IV Seminário Internacional Arquivos de Museu e Pesquisa, São Paulo, Universidade de São Paulo (USP), 28 e 29 de set de 2015. p. 211-219. Disponível em: http://www.mac.usp.br/mac/conteudo/ academico/publicacoes/anais/anais_IV_seminario.pdf. Acesso em 10 mar. 2020.

DERRIDA, Jacques. Mal de Arquivo: uma impressão freudiana.Trad. Cláudia de Moraes Rego. Rio de Janeiro: Relume Dumará, 2001.

DIDI-HUBERMAN, Georges. Contra todo e qualquer inimaginável/No próprio olho da história In: Imagens apesar de tudo, Lisboa: KKYM, 2012, p. 33-60.

GIUNTA, Andrea; FLAHERTY, George F. "Latin American Art History: An Historiographic Turn". In: Art in Translation, 9: sup1, 2017, pp. 121-142.

KRAUSS, Rosalind. Corpus Delict In: O Fotográfico, Barcelona: editorial Gustavo Gili, 2002, p. 171-204.

MATTOS, Ana Luiza. Arquivo Histórico Wanda Svevo: An Archive that was Once Dead. Moscow, Russia, 2017. (15m12s). Disponível em: <https:// www.youtube.com/Qqydnu_jvJk>. Acesso em 22 mar. 2020.

PREZIOSI, Donald. Collecting/Museums. In: NELSON, Robert S.; SHIFF, Richard. Critical terms for art history. 2. ed. Chicago/London: The University of Chicago Press, 2003, p. 407-418.

SELIGMANN-SILVA, Márcio. Sobre o anarquivamento - um encadeamento a partir de Walter Benjamin. Revista Poiésis, n. 24, p. 35-58, Niterói: Dezembro de 2014. Disponível em <http://www.poiesis.uff.br/p24/pdf/ p24-dossie-3-marcio-seligmann-silva.pdf>. Acesso em 04 ago. 2019. 
SOLIS, Dirce Eleonora Nigro. Tela desconstrucionista: arquivo e mal de arquivo a partir de Jacques Derrida. Rev. Filos., Aurora, Curitiba, v. 26, n. 38, p. 373-389, jan./jun. 2014. Disponível em <https://periodicos.pucpr.br/index.php/aurora/article/view/1096/1021>. Acesso em 02 ago. 2019.

Recebido em 30 de março de 2020 e aceito em 15 de abril de 2020.

Este é um artigo publicado em acesso aberto sob uma licença Creative Commons (cc) $)$ EY 